\title{
Efeito da adição de plasma seminal oriundo de animais de alta e baixa fertilidade na criopreservação de espermatozoides da cauda do epidídimo e do ejaculado de garanhões subférteis
}

[Effect of seminal plasma addition from high and low fertility animals on the cryopreservation of F.P. Hartwig ${ }^{2}$, P.M. Papa ${ }^{2}$, J. Pantoja ${ }^{2}$, D.F. Silva ${ }^{1}$, F.O. Papa ${ }^{2}$

${ }^{1}$ Universidade Federal de Minas Gerais - Belo Horizonte, MG

${ }^{2}$ Universidade Estadual Paulista - Botucatu, SP

${ }^{3}$ Universidade Federal de Viçosa - Viçosa, MG

\section{RESUMO}

O objetivo do presente estudo foi avaliar o efeito da adição de plasma seminal de garanhões de alta e baixa fertilidade sobre a congelabilidade e a viabilidade de espermatozoides do ejaculado (EJ) e do epidídimo (EP) de garanhões subférteis. Foram utilizados seis garanhões com histórico de subfertilidade. Após coleta, espermatozoides do ejaculado foram divididos em três alíquotas: BotuSêmen ${ }^{\circledR}($ EJ-CT); plasma seminal de alta qualidade espermática (EJ-PS1); e plasma seminal de baixa qualidade espermática (EJ-PS2). O mesmo protocolo foi realizado com espermatozoides da cauda do epidídimo após orquiectomia (EP-CT; EP-PS1; EPPS2). Foram realizadas avaliações da cinética espermática pelo CASA e análises de integridade de membrana, acrossoma, fragmentação de DNA, capacitação espermática e peroxidação espermática por citometria de fluxo. Não foram observadas diferenças na cinética espermática entre EJ e EP, logo após a descongelação. Porém, foi observada maior $(\mathrm{P}<0,05)$ porcentagem de células com membranas plasmática e acrossomal íntegras nos

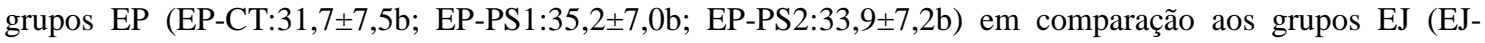

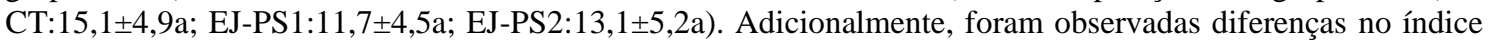

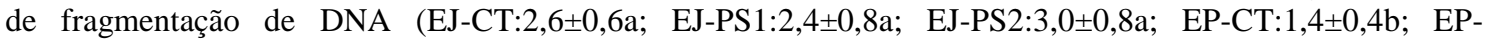
PS1:1,2 $\pm 0,3 b$; EP-PS2:1,3 $\pm 0,2 b$ ). Concluiu-se que a adição de $20 \%$ de plasma seminal, oriundo de animais férteis ou subférteis, previamente à congelação de espermatozoides epidídimários de animais subférteis não interfere na qualidade espermática.

Palavras-chave: equino, cauda do epidídimo, subfertilidade, sêmen

\section{ABSTRACT}

The aim of this study was to compare the effect of the addition of seminal plasma from high and low fertility stallions on sperm viability of frozen-thawed sperm cells from ejaculate and from epididymal tail of subfertile stallions. Six stallions with a history of subfertility were used. After collection, ejaculate spermatozoa were divided into three aliquots: Botu-Semen ${ }^{\circledR}(E J-C T)$; High-quality seminal plasma (EJ-PS1); Low-quality seminal plasma (EJ-PS2). The same was done with sperm cells from epididymis tail after orchiectomy (EP-CT; EP-PS1; EP-PS2). Evaluations of sperm kinetics were assessed by CASA and membrane and acrosome integrity, DNA fragmentation, sperm capacitation and sperm peroxidation were assessed by flow cytometry. After thawing, no differences were observed between ejaculated sperm (EJ) and epididymal sperm (EP) in any CASA evaluations. However, higher $(P<0.05)$ percentage of cells with intact plasma and acrossomal membranes was observed in EP groups (EP-CT:31.7 $\pm 7.5 b ; E P-P S 1: 35.2 \pm 7.0 b ; E P-P S 2: 33.9 \pm 7.2 b)$ compared

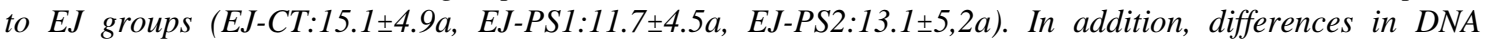
fragmentation index were observed (EJ-CT:2.6 $\pm 0.6 a ; E J-P S 1: 2.4 \pm 0.8 a ; E J-P S 2: 3.0 \pm 0.8 a ; C T: 1.4 \pm 0.4 b ; E P$ $P S 1: 1.2 \pm 0.3 b$; EP-PS2:1.3 $\pm 0.2 b$ ). It was concluded that the addition of $20 \%$ seminal plasma from fertile or subfertile animals prior to the freezing of epididymal spermatozoa from subfertile animals does not interfere in sperm quality.

Keywords: equine, tail of epididymis, subfertility, semen

Recebido em 25 de janeiro de 2018

Aceito em 20 de dezembro de 2018

E-mail: monteiroga@yahoo.com.br 


\section{INTRODUÇÃO}

À medida que os espermatozoides passam pelo epidídimo, eles sofrem importantes alterações morfofuncionais. $\mathrm{O}$ efeito fisiológico da aquisição de macromoléculas nesse trajeto não é completamente elucidado, mas é requerido para o desenvolvimento de motilidade e capacidade fecundante (Jones, 1998), de modo que melhores taxas de fertilização são obtidas utilizando espermatozoides recuperados da cauda do epidídimo quando comparado a amostras coletadas da cabeça e do corpo (Holtz e Smidt, 1976).

Após a maturação, os espermatozoides são armazenados na cauda do epidídimo e, ao serem ejaculados, sofrem diversas transformações na membrana devido ao contato com a secreção proveniente das glândulas acessórias (Boué et al., 1996). O plasma seminal corresponde a um fluido produzido pela rete testis, epidídimo e glândulas acessórias. Esse fluido é expelido em frações durante a ejaculação e tem a função de transportar e fornecer substratos metabólicos importantes para o desenvolvimento dos espermatozoides, além de participar do processo de maturação espermática (Troedsson et al., 2005). Entretanto, o efeito da adição do plasma seminal ao sêmen é contraditório, tendo em vista a grande variabilidade na composição bioquímica desse fluido entre garanhões (Aurich et al., 1996; Love et al., 2010; Guasti et al.,2012a).

Diversos estudos têm questionado a necessidade do plasma seminal no processo de fecundação, já que espermatozoides recuperados da cauda do epidídimo, que não possuem contato com essas secreções, foram capazes de fertilizar o ovócito (Papa et al., 2008; Monteiro et al., 2011a; Monteiro et al., 2011b), podendo apresentar alta taxa de concepção. Além disso, algumas pesquisas relataram que o plasma seminal pode causar prejuízos relacionados à fertilidade e congelabilidade espermática (Moore e Hibbit, 1976; Aurich et al., 1996).

Monteiro et al. (2011b) demonstraram que parâmetros da cinética de espermatozoides epididimários melhoraram consideravelmente após centrifugação seguida da adição de meio diluidor para congelação de sêmen equino $\left(\right.$ BotuCrio $\left.^{\mathrm{TM}}\right)$. Isso porque a diluição do fluido epididimário, com plasma seminal ou com diluidores de sêmen, permite o início da motilidade espermática e a ativação de seu metabolismo (Turner e Reich, 1985).

Alguns garanhões apresentam sêmen com baixa capacidade de refrigeração e/ou congelação, provavelmente por alterações nas composições proteicas e/ou lipídicas das membranas espermáticas. Componentes presentes no plasma seminal podem se incorporar à membrana espermática, tornando o sêmen mais (ou menos) resistente aos processamentos envolvendo redução da temperatura seminal (Hartwig et al., 2014).

Considerando a hipótese de que o plasma seminal de animais de baixa fertilidade interfere negativamente na qualidade espermática, $o$ objetivo do presente estudo foi comparar o efeito da adição de plasma seminal proveniente de garanhões de alta e baixa fertilidade sobre a congelabilidade e a viabilidade dos espermatozoides do ejaculado (EJ) e daqueles recuperados da cauda do epidídimo (EP) de garanhões subférteis.

\section{MATERIAL E MÉTODOS}

O presente estudo foi aprovado pela Comissão de Ética no Uso de Animais da Faculdade de Medicina Veterinária e Zootecnia (FMVZ) da Unesp (Botucatu, SP), sob protocolo no 37/2010Ceua. Foram utilizados seis garanhões com histórico de subfertilidade, de diferentes raças (três Mangalargas Paulista, dois Mangalargas Machador e um Lusitano). Os animais apresentavam entre cinco e 10 anos de idade e parâmetros de motilidade total e progressiva menores que $50 \%$ e $25 \%$, respectivamente.

Inicialmente, três ejaculados de cada garanhão foram coletados com intervalo de dois dias, com o objetivo de eliminar possíveis células degeneradas da cauda do epidídimo, ducto deferente e ampola, visando estabilizar os parâmetros espermáticos. Os seis animais foram utilizados nos grupos 1 (EJ) e 2 (EP), sendo, portanto, seus próprios controles.

No grupo 1 (EJ), foram coletados, com intervalo de uma semana, dois ejaculados de cada garanhão utilizando-se vagina artificial. Após a retirada da fração gelatinosa, a amostra seminal foi diluída na proporção 1:1 (v/v) com diluente BotuSêmen® (diluidor para manutenção de 
sêmen equino à base de leite, Botupharma Ltda., Brasil) e dividida em três alíquotas, as quais foram acrescidas de $20 \%$ (v/v) com os seguintes meios: BotuSêmen ${ }^{\circledR}($ EJ-CT); plasma seminal de garanhões com alta qualidade espermática (EJPS1); plasma seminal de garanhões com baixa qualidade espermática (EJ-PS2).

Todas as amostras foram incubadas por $15 \mathrm{~min}$ a $37^{\circ} \mathrm{C}$ e posteriormente centrifugadas a $600 \mathrm{xg}$ por 10min. O sobrenadante foi desprezado, e o "pellet" ressuspendido com o diluente BotuCrio® (diluidor para congelação de sêmen equino contendo glicerol, Botupharma Ltda., Brasil), na concentração de $100 \times 10^{6}$ espermatozoides totais por $\mathrm{mL}$.

Após o envase, as palhetas de $0,5 \mathrm{~mL}$ foram colocadas em geladeira e permaneceram na temperatura de $5^{\circ} \mathrm{C}$ por $20 \mathrm{~min}$. Posteriormente, foram acondicionadas em caixa isotérmica com capacidade de 45 litros, preenchida com nitrogênio líquido até a marca de $3,5 \mathrm{~cm}$ de altura. As palhetas ficaram dispostas horizontalmente a $6,0 \mathrm{~cm}$ do nível do nitrogênio líquido por 20min e, após esse período, foram imersas nele.

Uma semana após a última coleta de sêmen com vagina artificial, os garanhões foram submetidos à orquiectomia bilateral. Imediatamente após o procedimento, realizou-se a coleta dos espermatozoides da cauda do epidídimo pela técnica de fluxo retrógrado descrita por Garde et al. (1994). Em seguida, o ducto epididimário foi lavado injetando-se o diluente (BotuSêmen ${ }^{\circledR}$ ) no lúmen dele, fazendo com que os espermatozoides fossem carreados pelo diluente.

Após a recuperação dos espermatozoides do epidídimo (EP), as amostras seminais foram diluídas até atingirem a concentração de $80 \times 10^{6} / \mathrm{mL}$, com o diluente BotuSêmen ${ }^{\circledR}$. Posteriormente a amostra seminal foi dividida em três grupos, e cada grupo acrescido de $20 \%$ $(\mathrm{v} / \mathrm{v})$ com os seguintes meios: BotuSêmen ${ }^{\circledR}(\mathrm{EP}-$ CT); plasma seminal de garanhões com alta qualidade espermática (EP-PS1); plasma seminal de garanhões com baixa qualidade espermática (EP-PS2). Após adição, as amostras foram incubadas por $15 \mathrm{~min}$ a $37^{\circ} \mathrm{C}$. A congelação dos espermatozoides do epidídimo após a coleta seguiu o mesmo protocolo descrito para a congelação do sêmen do ejaculado (EJ), anteriormente descrito.
Embora exista grande divergência quanto à influência do plasma seminal nas taxas de fertilidade, alguns autores demonstraram necessária a manutenção de 5 a $20 \%$ desse componente do ejaculado para aumentar a viabilidade dos espermatozoides (Jasko et al., 1992; Loomis, 2006). Assim, o presente estudo baseou-se na maior concentração referenciada, a fim de avaliar o efeito da adição do componente.

Para a coleta de plasma seminal, foram utilizados seis garanhões subférteis no grupo de baixa qualidade seminal (sêmen fresco com motilidade total $<50 \%$ e histórico de fertilidade $<20 \%$ ) e seis garanhões férteis no grupo de alta qualidade seminal (sêmen fresco com motilidade total $>80 \%$ e fertilidade $>80 \%$ ). Após a coleta do sêmen com vagina artificial, o ejaculado foi centrifugado em tubos plásticos de $15 \mathrm{~mL}$ a $1000 x g$ por $15 \mathrm{~min}$, repetindo-se o procedimento por três vezes, trocando-se o frasco sem ressuspensão do pellet. O sobrenadante final foi envasado em criotubos e congelado em freezer a $-20^{\circ} \mathrm{C}$. Previamente à adição do plasma seminal aos espermatozoides, as amostras de plasma seminal foram mantidas em banho-maria até atingirem a temperatura de $37^{\circ} \mathrm{C}$ e, somente nesse momento, foram adicionadas aos espermatozoides.

Os espermatozoides coletados com vagina artificial e da cauda do epidídimo foram avaliados pelo método CASA (aparelho Hamilton Thorne Research; HTM IVOS, EUA) imediatamente após a incubação (M1) e imediatamente após a descongelação (M2). Para avaliação das amostras descongeladas, utilizouse banho-maria a $46^{\circ} \mathrm{C}$ por 20 segundos (Dell'Aqua Jr. et al., 2001). Os seguintes parâmetros da cinética espermática foram avaliados: motilidade total (MT; \%), motilidade progressiva (MP; \%) espermatozoides rápidos (RAP; \%), velocidade progressiva (VSL; $\mu \mathrm{m} / \mathrm{s}$ ) e velocidade de trajeto (VAP; $\mu \mathrm{m} / \mathrm{s}$ ).

Todas as análises de citometria de fluxo foram realizadas no sêmen após a descongelação das palhetas a $46^{\circ} \mathrm{C}$ por 20 s (M2), com exceção da avaliação da integridade de membrana plasmática, que foi avaliada após a incubação e após a descongelação (M1 e M2). Para essas análises, foi utilizado o equipamento BD LSR Fortessa (Becton Dickinson, EUA), equipado com lasers: azul 488-nm, 100mW, vermelho 
640nm, 40mW e violeta 405nm, 100mW. Após a análise, os dados foram arquivados para posterior avaliação, por meio do software FACSDiva ${ }^{\mathrm{TM}}$ software V6,2.

Para a avaliação de integridade das membranas plasmática e acrossomal, foram utilizadas as sondas iodeto de propídio (IP; P4170, Sigma Chemical Company, EUA) e FITC-PSA (L0770, Sigma) acrescido da adição de Hoechst 33345 (14533, Sigma), de acordo com FreitasDell’Aqua et al. (2012). Assim, em uma amostra de $100 \mu \mathrm{L}$ de sêmen diluído em TALP na concentração de $10 \times 10^{6}$ espermatozoides $/ \mathrm{mL}$, foram adicionados $1,5 \mu \mathrm{M}$ de IP e $0,2 \mathrm{ng}$ de FITC-PSA e $7.0 \mu \mathrm{M}$ de Hoechst, e, então, homogeneizados e incubados por $10 \mathrm{~min}$ a $37^{\circ} \mathrm{C}$; após a incubação, foram acrescidos $400 \mu \mathrm{L}$ de TALP para uma leitura de 500 a 600 eventos/s.

A avaliação da peroxidação das membranas espermáticas foi realizada utilizando-se a probe C11-BODYPY (D-3861; Molecular Probes Inc., EUA). Assim, em uma alíquota de $100 \mu \mathrm{L}$ do sêmen diluído em TALP a uma concentração de $10 \times 10^{6}$ espermatozoides $/ \mathrm{mL}$, foram acrescidos mais $399,5 \mu \mathrm{L}$ de TALP, para uma concentração de $1 \times 10^{6}$ espermatozoides e $0,5 \mu \mathrm{L}$ da sonda C11BODIPY581/591 (1mg/mL; Molecular Probes) por $20 \mathrm{~min}$ a $37^{\circ} \mathrm{C}$. Após o período de incubação, a amostra foi centrifugada a $300 \mathrm{~g}$ por 5 min e ressuspendida para $500 \mu \mathrm{L}$, e, então, foram adicionados $1,5 \mu \mathrm{M}$ de IP e $7,0 \mu \mathrm{M}$ de Hoechst (Guasti et al., 2012b). A amostra foi novamente incubada por $10 \mathrm{~min}$ a $37^{\circ} \mathrm{C}$. Para a avaliação da peroxidação das membranas espermáticas, foram consideradas apenas as células com a membrana plasmática íntegra (IP negativo) e marcadas para peroxidação da membrana plasmática.

A avaliação do índice da fragmentação do DNA foi realizada com uma amostra de $100 \mu \mathrm{L}$ de sêmen diluído, em solução tampão na concentração de $1 \times 10^{6}$ espermatozoides $/ \mathrm{mL}$, foram adicionados $400 \mu \mathrm{L}$ de solução detergente ácida. Esta foi incubada por 30 s, e, então, foi acrescido $1 \mathrm{~mL}$ de solução corante de laranja de acridina (AO), a qual foi incubada por mais 30s ao abrigo da luz. O índice de fragmentação de DNA (IFDNA) foi gerado com base na análise de 10.000 células marcadas com AO. O IFDNA é a proporção (\%) do DNA fragmentado (fluorescência vermelha) dividida pela fluorescência total (soma do DNA fragmentado com o DNA não fragmentado).

Para a avaliação da capacitação espermática, em $100 \mu \mathrm{L}$ de sêmen (previamente diluído em TALP, na concentração de $10 \times 10^{6}$ espermatozoides $/ \mathrm{mL}$ ), foram acrescidos $900 \mu \mathrm{L}$ de TALP para uma concentração final de $1 \times 10^{6}$ espermatozoides. Dessa nova concentração, $150 \mu \mathrm{L}$ foram colocados em um tubo de $5 \mathrm{~mL}$, e, então, adicionaram-se $5 \mu \mathrm{L}$ de IP $(50 \mu \mathrm{g} / \mathrm{mL})$ e $5 \mu \mathrm{L}$ de Hoechst $(100 \mu \mathrm{g} / \mathrm{mL})$, que foram incubados por $10 \mathrm{~min}$ a $37^{\circ} \mathrm{C}$ (Andrade et al., 2012). Após a incubação, adicionaram-se $5 \mu \mathrm{L}$ do anticorpo antifosfotirosina $(100 \mu \mathrm{g} / \mathrm{mL}$; CLONE PY-20, F0426; Sigma), previamente diluído em uma solução supersaturada de O-Phospho-Ltyrosine (P9405, Sigma), de modo que a concentração final do anticorpo fosse $2 \mu \mathrm{g} / \mathrm{mL}$. Posteriormente, a solução final ficou incubada por mais $5 \mathrm{~min}$ nas mesmas condições. Para a avaliação da capacitação espermática, foram consideradas apenas as células com membrana plasmática íntegra (IP negativo) e marcadas com o anticorpo.

Por fim, realizou-se ainda a avaliação da translocação de fosfatidilserina da membrana. Para essa avaliação, foram utilizadas as sondas anexina V-APC (550475; BD Pharmingen, BD Biosciences, EUA), conforme as recomendações do laboratório, acrescidas de Hoechst 33345 (14533, Sigma), de acordo com Freitas-

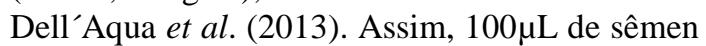
diluído em TALP na concentração de 10×10 espermatozoides/mL foram adicionados em um tubo de cultura de $5 \mathrm{~mL}$ e, então, acrescentaramse $5 \mu \mathrm{L}$ de anexina V-FITC, $5 \mu \mathrm{L}$ de IP $(50 \mu \mathrm{g} / \mathrm{mL}), \quad 5 \mu \mathrm{L}$ de Hoechst $(100 \mu \mathrm{g} / \mathrm{mL})$ e $400 \mu \mathrm{L}$ de solução tampão de anexina $\mathrm{V}(\mathrm{pH} 7,4)$. As amostras foram homogeneizadas e incubadas por $15 \mathrm{~min}$ em temperatura ambiente. As células observadas durante a análise foram classificadas como células mortas (PI positivo), células viáveis sem translocação de fosfatidilserina (An/IP-) e células viáveis com translocação fosfatidilserina (An+/PI-). $O$ índice de translocação de fosfatidilserina (translocação de fosfolipídios de membrana; ANEX) foi calculado com base na relação entre o número de An+/PI- e o número total de An-/PI- (Ricci et al., 2002).

Inicialmente a distribuição das varáveis foi analisada e as estatísticas descritivas foram 
produzidas para construir curvas de variação longitudinal para cada parâmetro espermático. As varáveis MT e MP foram transformadas para a escala arco seno para atingir normalidade. Para as outras variáveis normalmente distribuídas (VAP e VSL), modelos de medidas repetidas (PROC MIXED, SAS Institute Inc., Copyright (C) 2009) foram usados para comparar a média de cada parâmetro espermático entre os tratamentos.

Um termo de interação entre tratamento e momento foi incluído em todos os modelos para testar a hipótese de que a diferença entre tratamentos foi dependente do momento analisado. Uma estrutura de covariância autorregressiva foi usada para modelar a correlação entre as medidas repetidas dentro do mesmo animal. O teste de Tukey foi empregado para ajustar os valores-P resultantes de comparações múltiplas. Para os parâmetros RAP, PMAI, ANEX, IFDNA, CAP e PER, utilizou-se o teste de Wilcoxon (SAS PROC NPAR1WAY) para comparar a mediana de cada variável entre os grupos, dentro de cada momento. O nível de significância estatística foi definido em $\mathrm{P}<0,05$.

\section{RESULTADOS}

Não foram observadas diferenças entre grupos em nenhuma das avaliações do CASA, realizadas logo após a incubação (M1) e logo após a descongelação (M2). Porém, foi observada maior porcentagem de células com membrana plasmática íntegra nos espermatozoides epididimários em comparação aos espermatozoides do ejaculado, conforme demonstrado nas Tab. 1 e 2 .

Tabela 1. Média ( \pm desvio-padrão) de motilidade total (MT), motilidade progressiva (MP), velocidade angular progressiva (VAP), velocidade linear progressiva (VSL) e espermatozoides rápidos (RAP) e integridade de membrana plasmática (IMP) dos espermatozoides do ejaculado (EJ-CT, EJ-PS1, EJ-PS2) e dos espermatozoides do epidídimo (EP-CT, EP-PS1, EP-PS2) de garanhões subférteis imediatamente após a incubação (M1)

\begin{tabular}{lcccccc}
\multicolumn{1}{c}{ Grupos } & MT $(\%)$ & MP $(\%)$ & VAP $(\mu \mathrm{m} / \mathrm{s})$ & VSL $(\mu \mathrm{m} / \mathrm{s})$ & RAP $(\%)$ & IMP $(\%)$ \\
\hline EJ-CT & $24,2 \pm 16,1$ & $8,5 \pm 8,5$ & $101,3 \pm 14,3$ & $73,3 \pm 8,7$ & $17,5 \pm 12,9$ & $32,2 \pm 7,6 \mathrm{a}$ \\
EJ-PS1 & $26,0 \pm 17,2$ & $9,0 \pm 9,9$ & $102,3 \pm 8,4$ & $71,3 \pm 7,9$ & $18,8 \pm 12,8$ & $34,2 \pm 9,4 \mathrm{a}$ \\
EJ-PS2 & $22,2 \pm 16,4$ & $7,5 \pm 8,1$ & $101,7 \pm 14,6$ & $69,8 \pm 9,0$ & $16,0 \pm 13,1$ & $33,0 \pm 10,0 \mathrm{a}$ \\
EP-CT & $14,5 \pm 11,0$ & $5,0 \pm 4,7$ & $89,8 \pm 7,5$ & $69,7 \pm 9,7$ & $25,3 \pm 21,2$ & $80,8 \pm 4,4 \mathrm{~b}$ \\
EP-PS1 & $28,0 \pm 24,2$ & $13,0 \pm 14,5$ & $92,3 \pm 14,2$ & $75,3 \pm 10,0$ & $20,5 \pm 22,6$ & $79,0 \pm 9,2 \mathrm{~b}$ \\
EP-PS2 & $22,8 \pm 20,7$ & $7,8 \pm 6,2$ & $84,3 \pm 7,9$ & $68,2 \pm 7,2$ & $12,3 \pm 10,6$ & $82,7 \pm 6,2 \mathrm{~b}$ \\
\hline
\end{tabular}

Letras diferentes na mesma coluna diferem entre si $(\mathrm{P}<0,05)$.

$\mathrm{CT}=$ grupos incubados com 20\% BotuSêmen, $\mathrm{PS} 1=$ grupos incubados com $20 \%$ plasma seminal de garanhões com alta qualidade espermática, PS2 = grupos incubados com $20 \%$ plasma seminal de garanhões com baixa qualidade espermática.

Tabela 2. Média ( \pm desvio-padrão) de motilidade total (MT), motilidade progressiva (MP), velocidade angular progressiva (VAP), velocidade linear progressiva (VSL) e espermatozoides rápidos (RAP) e integridade de membrana plasmática (IMP) dos espermatozoides do ejaculado (EJ-CT, EJ-PS1, EJ-PS2) e dos espermatozoides do epidídimo (EP-CT, EP-PS1, EP-PS2) de garanhões subférteis após descongelação (M2)

\begin{tabular}{lcccccc}
\multicolumn{1}{c}{ Grupos } & MT $(\%)$ & MP $(\%)$ & VAP $(\mu \mathrm{m} / \mathrm{s})$ & VSL $(\mu \mathrm{m} / \mathrm{s})$ & RAP $(\%)$ & IMP $(\%)$ \\
\hline EJ-CT & $16,3 \pm 15,1$ & $7,5 \pm 8,5$ & $75,8 \pm 22,9$ & $66,2 \pm 15,3$ & $10,2 \pm 11,4$ & $15,2 \pm 4,8 \mathrm{a}$ \\
EJ-PS1 & $9,7 \pm 10,0$ & $4,2 \pm 6,3$ & $77,2 \pm 23,4$ & $67,5 \pm 24,4$ & $5,5 \pm 7,6$ & $12,0 \pm 4,5 \mathrm{a}$ \\
EJ-PS2 & $13,8 \pm 9,8$ & $5,7 \pm 6,6$ & $74,7 \pm 17,5$ & $63,3 \pm 14,4$ & $7,8 \pm 8,1$ & $13,3 \pm 5,3 \mathrm{a}$ \\
EP-CT & $29,7 \pm 8,8$ & $10,7 \pm 8,0$ & $76,3 \pm 12,1$ & $64,3 \pm 10,4$ & $15,5 \pm 9,2$ & $32,1 \pm 7,7 \mathrm{~b}$ \\
EP-PS1 & $22,8 \pm 18,1$ & $9,5 \pm 11,9$ & $69,7 \pm 15,0$ & $59,3 \pm 13,3$ & $12,3 \pm 14,1$ & $35,5 \pm 7,1 \mathrm{~b}$ \\
EP-PS2 & $24,2 \pm 13,9$ & $8,8 \pm 9,2$ & $71,2 \pm 14,3$ & $60,2 \pm 12,2$ & $12,1 \pm 11,1$ & $34,1 \pm 7,3 \mathrm{~b}$ \\
\hline
\end{tabular}

Letras diferentes na mesma coluna diferem entre si $(\mathrm{P}<0,05)$.

$\mathrm{CT}=$ grupos incubados com 20\% BotuSêmen, PS1= grupos incubados com $20 \%$ plasma seminal de garanhões com alta qualidade espermática, PS2= grupos incubados com $20 \%$ plasma seminal de garanhões com baixa qualidade espermática. 
Adicionalmente, logo após a descongelação (M2), foram observadas diferenças na porcentagem de células apresentando integridade de membranas plasmática e acrossomal e no índice de fragmentação de DNA entre os grupos de sêmen oriundos do EJ daqueles oriundos do EP. Os resultados das análises seminais realizadas por citometria de fluxo estão demonstrados na Tab. 3.

Tabela 3. Média ( \pm desvio-padrão) de integridade de acrossoma (IA), integridade de membrana plasmática e acrossoma íntegros (PMAI), índice de fragmentação de DNA (IFDNA), translocação de fosfolipídios de membrana (ANEX), capacitação espermática (CAP) e peroxidação das membranas espermáticas (PER) dos espermatozoides do ejaculado (EJ-CT, EJ-PS1, EJ-PS2) e dos espermatozoides do epidídimo (EP-CT, EP-PS1, EP-PS2) de garanhões subférteis após a descongelação (M2)

\begin{tabular}{lcccccc}
\hline \multicolumn{1}{c}{ Grupos } & IA (\%) & PMAI (\%) & IFDNA (\%) & ANEX (\%) & CAP (\%) & PER (\%) \\
\hline EJ-CT & $54,7 \pm 7,6 \mathrm{a}$ & $15,1 \pm 4,9 \mathrm{a}$ & $2,6 \pm 0,6 \mathrm{a}$ & $7,0 \pm 10,8$ & $3,4 \pm 2,5$ & $6,2 \pm 4,7$ \\
EJ-PS1 & $53,5 \pm 10,9 \mathrm{a}$ & $11,7 \pm 4,5 \mathrm{a}$ & $2,4 \pm 0,8 \mathrm{a}$ & $6,5 \pm 6,4$ & $3,2 \pm 3,2$ & $7,0 \pm 5,3$ \\
EJ-PS2 & $56,3 \pm 7,6 \mathrm{a}$ & $13,1 \pm 5,2 \mathrm{a}$ & $3,0 \pm 0,8 \mathrm{a}$ & $2,9 \pm 2,7$ & $3,9 \pm 3,9$ & $8,3 \pm 4,4$ \\
EP-CT & $70,9 \pm 5,5 \mathrm{~b}$ & $31,7 \pm 7,5 \mathrm{~b}$ & $1,4 \pm 0,4 \mathrm{~b}$ & $2,9 \pm 2,8$ & $1,4 \pm 1,2$ & $7,2 \pm 5,0$ \\
EP-PS1 & $72,5 \pm 4,5 \mathrm{~b}$ & $35,2 \pm 7,0 \mathrm{~b}$ & $1,2 \pm 0,3 \mathrm{~b}$ & $2,1 \pm 1,1$ & $1,6 \pm 0,9$ & $8,7 \pm 5,5$ \\
EP-PS2 & $73,4 \pm 5,7 \mathrm{~b}$ & $33,9 \pm 7,2 \mathrm{~b}$ & $1,3 \pm 0,2 \mathrm{~b}$ & $3,6 \pm 2,6$ & $1,1 \pm 1,1$ & $7,7 \pm 5,5$ \\
\hline
\end{tabular}

Letras diferentes na mesma coluna diferem entre si $(\mathrm{P}<0,05)$.

$\mathrm{CT}=$ grupos incubados com $20 \%$ BotuSêmen, PS1= grupos incubados com $20 \%$ plasma seminal de garanhões com alta qualidade espermática, PS2 = grupos incubados com $20 \%$ plasma seminal de garanhões com baixa qualidade espermática.

\section{DISCUSSÃO}

Antigamente, acreditava-se ser essencial a presença do plasma seminal no processo de fecundação. Contudo, pesquisas demonstram que espermatozoides provenientes da cauda do epidídimo, sem qualquer contato com plasma seminal, têm qualidade espermática e fertilidade igual ou superior aos espermatozoides do ejaculado (Tiplady et al., 2002; Monteiro et al., 2011b). O efeito do plasma seminal sobre os parâmetros de cinética espermática pré e póscongelação foi investigado por inúmeros estudos (Braun et al., 1994; Tiplady et al., 2002; Heise et al., 2011), apresentando, no entanto, resultados contraditórios. Alguns relataram efeito benéfico da adição de plasma seminal nas amostras do epidídimo sobre os parâmetros de cinética espermática (Braun et al., 1994; Tiplady et al., 2002); outros, no entanto, relataram que o plasma seminal pode causar prejuízos à fertilidade e à congelabilidade do sêmen (Moore e Hibbit, 1976; Moustafa e Meszaros, 1981). No presente estudo, não foi observada diferença nos parâmetros de cinética espermática entre espermatozoides do epidídimo com adição de $20 \%$ de plasma seminal (EP-PS1 e EP-PS2) e sem adição de plasma seminal (EP-CT).

Esses achados são contraditórios aos reportados por Tiplady et al. (2002) e por Neuhauser et al.
(2013), que relataram um efeito estimulador quando o plasma seminal foi adicionado a espermatozoides epididimários. As diferenças do momento da adição, bem como as diferentes concentrações de plasma seminal, provavelmente contribuíram para resultados contraditórios entre os estudos. Além disso, a interação do plasma seminal com fatores do leite contidos no meio extensor pode influenciar os resultados (Mari et al., 2011).

No presente estudo, as análises realizadas nos momentos M1 e M2 demonstraram similaridade nos parâmetros da cinética espermática dos espermatozoides do ejaculado (EJ-CT, EJ-PS1 e EJ-PS2) quando comparados aos recuperados da cauda do epidídimo (EP-CT, EP-PS1 e EP-PS2). Esses achados são compatíveis aos resultados obtidos em garanhões de alta congelabilidade espermática (Monteiro et al., 2011b) e divergem de resultados obtidos em garanhões subférteis por Monteiro et al. (2011a), que apresentaram inferioridade nos parâmetros MT, MP e RAP dos espermatozoides do ejaculado, antes e após descongelação espermática. Porém, foi interessante notar que, tanto após a incubação quanto após a descongelação, EP apresentaram maior IMP que espermatozoides EJ.

Em relação à viabilidade espermática, todos os grupos de espermatozoides do ejaculado 
apresentaram menor número de espermatozoides com integridade de membranas plasmática e acrossomal (PMAI), sendo tais achados importantes para a manutenção da capacidade fecundante do espermatozoide. Esses resultados indicam superioridade dos espermatozoides da cauda do epidídimo quando comparados aos do ejaculado (Tab. 3). Diferem, no entanto, de relatos anteriores de Monteiro et al. (2011b), que demonstram similaridade entre parâmetros dos espermatozoides do ejaculado e do epidídimo, e de Heise et al. (2011), que observaram efeito positivo e significativo na adição de plasma seminal aos espermatozoides do epidídimo. Entretanto, diferentemente desses relatos anteriores, o presente estudo utilizou garanhões com histórico de subfertilidade apresentando baixa qualidade espermática. Outros pesquisadores já haviam demonstrado efeito deletério na viabilidade espermática após a adição de plasmas seminais provenientes de garanhões de baixa congelabilidade (Aurich et al., 1996). Além disso, o estudo realizado por Monteiro et al. (2011a) demonstrou superioridade tanto nos parâmetros de cinética espermática quanto na morfologia espermática dos espermatozoides recuperados da cauda do epidídimo de garanhões subférteis, em relação aos coletados com vagina artificial.

Após a descongelação, foi constatado menor índice de fragmentação de DNA (IFDNA) nos grupos recuperados da cauda do epidídimo quando comparados aos do ejaculado (Tab. 3). Resultado semelhante foi reportado por Love et al. (2005), que demonstraram haver aumento da fragmentação do DNA espermático quando há presença do plasma seminal no sêmen refrigerado de garanhões, fato que pode ocasionar redução da fertilidade. Em relação à análise e à capacitação espermática (Tab. 3), não foram constatadas diferenças entre espermatozoides do ejaculado e do epidídimo. Esses achados contrastam com os relatados por Sostaric et al. (2010), que apresentaram valores mais elevados nos espermatozoides do ejaculado quando comparados aos recuperados do epidídimo. A ausência de contato dos espermatozoides recuperados da cauda do epidídimo com o plasma seminal pode ser uma causa dos melhores resultados dos parâmetros IFDNA e PMAI quando comparados aos do ejaculado. Essa hipótese é sustentada por estudos que relataram que a presença de proteínas contidas no plasma seminal pode promover alterações bioquímicas, as quais podem aumentar a permeabilidade da membrana e promoverem injúria celular, levando a danos na membrana plasmática, com prejuízos na fertilidade e congelabilidade espermática (Moore e Hibbit, 1976; Moustafa e Mezanos, 1981).

Ramires Neto et al. (2013) demonstraram que a presença do plasma seminal apresentou efeito deletério na qualidade e na viabilidade espermática de garanhões que apresentavam sêmen sensível ao processo de refrigeração. Adicionalmente, Monteiro et al. (2011a) constataram superioridade dos parâmetros de cinética e morfologia espermática de espermatozoides recuperados da cauda do epidídimo quando comparados a espermatozoides oriundos do ejaculado de garanhões. Os mesmos autores (Monteiro et al., 2013) demonstraram que espermatozoides epididimários demonstraram ser mais resistentes ao choque causado pelo frio no processo de criopreservação. Estes, quando descongelados, apresentaram valores semelhantes, se não melhores, de motilidade espermática quando comparados a espermatozoides ejaculados. Com isso, esses autores sugeriram haver um efeito deletério do contato dos espermatozoides com a secreção proveniente das glândulas acessórias durante o processo de ejaculação.

Os resultados obtidos neste estudo demonstraram que os espermatozoides do ejaculado sofrem uma interação deletéria ao terem contato com secreções das glândulas anexas no momento da ejaculação, com relação à resistência ao processo de congelação, levando à queda do número de espermatozoides com membrana plasmática e acrossoma íntegros após a descongelação. Além disso, os espermatozoides desse grupo apresentaram maior índice de fragmentação de DNA quando comparados aos recuperados da cauda do epidídimo. Diante do exposto, acreditase que, em animais que apresentem baixa qualidade seminal, a utilização da coleta fracionada ou de técnicas de processamento de sêmen (centrifugação ou filtragem) que diminuem a quantidade de plasma seminal pode ser uma alternativa para melhorar a expectativa de fertilidade nesses garanhões.

Apesar de alguns trabalhos avaliarem o efeito da adição de plasma seminal nos espermatozoides 
do epidídimo (Morris, 2002; Heise et al., 2011; Neuhauser et al., 2013), nenhum desses trabalhos avaliou a ação do plasma seminal nos espermatozoides do epidídimo e do ejaculado de garanhões subférteis. No presente estudo, a adição de $20 \%$ (v/v) de plasma seminal de garanhões de alta ou baixa fertilidade não causou efeito deletério nem benéfico, tanto nos espermatozoides do epidídimo quanto do ejaculado. Isso pode ter ocorrido pelo contato prévio do espermatozoide ao meio diluente à base de leite devido à interação do plasma seminal com fatores contidos no meio extensor (Mari et al., 2011), ou, ainda, pela baixa concentração de plasma seminal adicionado nas amostras.

\section{CONCLUSÃO}

A secreção proveniente das glândulas anexas no momento da ejaculação é deletéria à qualidade de espermatozoides criopreservados, afetando principalmente a integridade das membranas plasmática e acrossomal e o DNA espermático de garanhões subférteis. A adição de $20 \%$ de plasma seminal, oriundo de animais férteis ou subférteis, previamente à congelação de espermatozoides da cauda do epidídimo de garanhões subférteis não interfere na qualidade espermática.

\section{AGRADECIMENTO}

Os autores agradecem à Fundação de Amparo à Pesquisa do Estado de São Paulo - Fapesp (09/54605-5).

\section{REFERENCIAS}

ANDRADE, A.F.; ZAFFALON, F.G.; CELEGHINI, E.C. et al. Post-thaw addition of seminal plasma reduces tyrosine phosphorylation on the surface of cryopreserved equine sperm, but does not reduce lipid peroxidation. Theriogenology, v.77, p.1866-1872, 2012.

AURICH, J.E.; KÜHNE, A.; HOPPE, H. et al. Seminal plasma affects membrane integrity and motility of equine spermatozoa after cryopreservation. Theriogenology, v.46, p.791797, 1996.
BOUÉ, F.; BLAIS, J.; SULlIVAN, R. Surface localization of $\mathrm{P} 34 \mathrm{H}$, an epididymal protein, during maturation, capacitation, and acrosome reaction of human spermatozoa. Biol. Reprod., v.54, p.1009-1017, 1996.

BRAUN, J.; TORRES-BOGGINO, F.; HOCHI, $\mathrm{S}$. et al. Effect of seminal plasma on motion characteristics of epididymal and ejaculated stallion spermatozoa during storage at 5 degrees C. Dtsch Tier. Woch., v.101, p.319-22, 1994.

DELL'AQUA Jr, J.A.; PAPA, F.O.; ALVARENGA, M.A. et al. Effects of warming rate on sperm parameters and of insemination site and dose on the fertility of equine frozen semen. Anim. Reprod. Sci., v.68, p.344-346, 2001.

FREITAS-DELL'AQUA, C.P.; GUASTI, P.N.; MONTEIRO, G.A. et al. Flow cytometric analysis of fertile and subfertile frozen stallion spermatozoa. Anim. Reprod., v.9, p.941, 2012.

FREITAS-DELL'AQUA， C.P.; MONTEIRO, G.A.; DELL'AQUA Jr, J.A. et al. The effects of refrigeration temperature and storage time on apoptotic markers in equine semen. J. Equine Vet. Sci, v.33, p.27-30, 2013.

GARDE, J.; AGUADO, M.; PEREZ, S. et al. Physiological characteristics of epididymal spermatozoa from postmortem rams. Theriogenology, v.41, p.203, 1994.

GUASTI, P.N.; FREITAS-DELL'AQUA, C.P.; MAZIERO, R.R.D. et al. Validation of flow cytometry for assessment of membrane lipid peroxidation of equine spermatozoa. Anim. Reprod., v.9, p.929, 2012 b.

GUASTI, P.N.; MONTEIRO, G.A.; PAPA, F.O. Componentes do plasma seminal e sua influência sobre a criopreservação e fertilidade de espermatozoides equinos. Vet. Zootec., v.19, p.169-180, 2012a.

HARTWIG, F.P.; LISBOA, F.P.; HARTWIG, F.P. et al. Use of cholesterol-loaded cyclodextrin: an alternative for bad cooler stallions. Theriogenology, v.81, p.340-346, 2014.

HEISE, A.; THOMPSON, P.N.; GERBER, D. Influence of seminal plasma on fresh and postthaw parameters of stallion epididymal spermatozoa. Anim. Reprod. Sci., v.123, p.192201, 2011. 
HOLTZ, W.; SMIDT, D. The fertilizing capacity of epididymal spermatozoa in the pig. J. Reprod. Fert., v.46, p.227-229, 1976.

JASKO, D.J.; HATHAWAY, J.A.; SCHALTENBRAND, V.L. et al. Effect of seminal plasma and egg yolk on motion characteristics of cooled stallion spermatozoa. Theriogenology, v.37, p.1241-1252, 1992.

JONES, R. Plasma membrane structure and remodeling during sperm maturation in the epididymis. J. Reprod. Fert. Suppl., v.53, p.7384, 1998.

LOOMIS, P.R. Advanced methods for handling and preparation of stallion semen. Vet. Clin. N. Am. Equine. Pract., v.22, p.663-676, 2006.

LOVE, C.C.; BRINSKO, S.P.; RIGBY, S.L. et al. Relationship of seminal plasma level and extender type to sperm motility and DNA integrity. Theriogenology, v.63, p.1584-1591, 2005.

LOVE, C.C.; THOMPSON, J.A.; BRINSKO, S.P. et al. Effect of inter-stallion seminal plasma variability on motility, viability, and DNA integrity of cauda epididymal sperm. Anim. Reprod. Sci., v.121, p.191, 2010.

MARI, G.; CASTAGNETTI, C.; RIZZATO, G. et al. Density gradient centrifugation of sperm from a subfertile stallion and effect of seminal plasma addition on fertility. Anim. Reprod. Sci., v.126, p.96-100, 2011.

MONTEIRO, G.A.; FREITAS-DELL'AQUA, C.P.; GUASTI, P.N. et al. Comparison of apoptotic cells between cryopreserved ejaculated sperm and epididymal sperm in stallions. $J$. Equine Vet. Sci., v.33, p.552-556, 2013.

MONTEIRO, G.A.; PAPA, F.O.; GUASTI, P.N. et al. Fertility of epididymal cauda sperm from subfertile stallions. Vet. Zootec., v.18, p.255-263, 2011a.

MONTEIRO, G.A.; PAPA, F.O.; ZAHN, F.S. et al. Cryopreservation and fertility of ejaculated and epididymal stallion sperm. Anim. Reprod. Sci., v.127, p.197-201, 2011 b.

MOORE, H.D.M.; HIBBIT, K.C.S. The binding of labeled basic proteins by boar spermatozoa. $J$. Reprod. Fertil. Suppl., v.46, p.71-77, 1976.
MORRIS, L.; TIPLADY, C.; ALLEN, W.R. The in vivo fertility of cauda epididymal spermatozoa in the horse. Theriogenology, v.58, p.643-646, 2002.

MOUSTAFA, A.R.; MEZAROS, I. Interrelationship between the total protein content of bovine seminal plasma and behavior of spermatozoa after freezing-and-thawing. Acta. Vet. Acad. Sci. Hung., v.4, p.403-408, 1981.

NEUHAUSER, S.; RHEINFELD, S.; HANDLER, J. Motility of fresh and frozenthawed stallion sperm from three segments of the epididymal cauda and the effect of post-thaw seminal plasma addition on motility. J. Equine Vet. Sci., v.33, p.942-949, 2013.

PAPA, F.O.; MELO, C.M.; FIORATTI, E.G. et al. Freezing of stallion epididymal sperm. Anim. Reprod. Sci., v.107, p.293-301, 2008.

RAMIRES NETO, C.; MONTEIRO, G.A.; SOARES, R.F. et al. Effect of removing seminal plasma using a sperm filter on the viability of refrigerated stallion. J. Equine Vet. Sci., v.33, p.40-43, 2013.

RICCI, G.; PERTICARARI, S.; FRAGONAS, E. et al. Apoptosis in human sperm: its correlation with semen quality and the presence of leukocytes. Hum. Reprod., v.17, p.2665-2672, 2002.

SOSTARIC, E.; KRAAN, H.; STOUT, T.A.E. Role of seminal plasma in the attainment of fertilizing capacity by stallion epididymal sperm. Anim. Reprod. Sci, v.121, p.185-194, 2010.

TIPLADY, C.A.; MORRIS, L.H.A.; ALLEN, W.R. Stallion epididymal spermatozoa: prefreeze and post-thaw motility and viability after three treatments. Theriogenology, v.58, p.225-228, 2002.

TROEDSSON, M.H.T.; DESVOUSGES, A.S.; ALGHAMDI, A.S. et al. Components in seminal plasma regulating sperm transport and elimination. Anim. Reprod. Sci., v.89, p.171-186, 2005.

TURNER, T.T.; REICH, G.W. Cauda epididymidal sperm motility: a comparison among five species. Biol. Reprod., v.32, p.120128,1985 . 